\title{
TLC Procedure for Determination of Approximate Contents of Caffeine in Food and Beverages
}

\author{
Carmen Palacios*, Maria L. F. Salatino, Antonio Salatino \\ Department of Botany, Institute of Biosciences, University of São Paulo, São Paulo, Brazil \\ *Corresponding author: cpalacios@usp.br
}

\begin{abstract}
An inexpensive TLC method is proposed for quantification of caffeine in food and beverage commercial products. The extraction is carried out with dichloromethane and the residue is analyzed by thin layer chromatography. The chromatograms are sprayed with a reagent containing iodine for visualization and the area of the spots is determined by freely available software. A good correlation was observed between contents of caffeine and TLC spot areas. Quantification of caffeine was carried out for a medicine tablet, coffee and guarana powders, a kola soft drink and a yerba mate beverage. Values close to the contents expected or within the admitted ranges were obtained. The method may be inadequate if high precision is essential, but it might be useful if values approximate to the real caffeine contents are satisfactory. Since the method requires no costly equipment, it seems to be feasible for chemistry teaching at several academic levels.
\end{abstract}

Keywords: general public, first-year undergraduate, laboratory instruction, thin layer chromatography, undergraduate research, food chemistry, alkaloids

Cite This Article: Carmen Palacios, Maria L. F. Salatino, and Antonio Salatino, "TLC Procedure for Determination of Approximate Contents of Caffeine in Food and Beverages." World Journal of Chemical Education, vol. 5, no. 5 (2017): 148-152. doi: 10.12691/wjce-5-5-1.

\section{Introduction}

Caffeine (1,3,7-trimethylxanthine) is a stimulant of the central nervous system, relatively abundant in coffee and cacao beans, kola nuts, guarana berries and leaves of tea and yerba mate [1]. Worldwide, caffeine is the most consumed alkaloid, mainly in beverages such as tea, coffee and soft drinks. Common medicines widely consumed possess caffeine as one of their active components [2]. Food and Drug Administration (FDA) regards caffeine either as a drug or a functional food [3].

It is commonly assumed that caffeine reduces fatigue and enhances physical endurance, mental alertness and concentration. It is admitted that daily doses of caffeine below $250 \mathrm{mg}$ are safe [4]. Excessive consumption may cause accelerated heart rate, nervousness, anxiety and insomnia, particularly in people still lacking tolerance to caffeine, such as children and teen agers [2]. Care is also necessary regarding pregnant women, since high caffeine intake may have negative consequences on baby delivery and induce low weight of newborns [4].

Caffeine consumption has increased over the last decades. Frary and collaborators [1] estimated as $193 \mathrm{mg}$ the average daily consumption per capita in the USA in the period 1994-1998. However, the FDA estimation for daily caffeine consumption in 2012 was $300 \mathrm{mg}$ by adults and $100 \mathrm{mg}$ by teen agers [2]. Denmark, Finland and Brazil are countries with highest consumption by adult people, daily averages corresponding to 390, 329 and $300 \mathrm{mg}$, respectively [3]. It is expected that caffeine consumption will increase even further, due to the widening spread of the fitness culture, the assumption of caffeine thermogenic properties and the increasing popularity of energy drinks.

Analysis of caffeine is a convenient theme in chemistry education. It is a drug familiar to people of all continents, who consume it every day and are curious about its real effects. Many analytical methods have been proposed for detection and evaluation of the quantity of caffeine in distinct materials, such as biological fluids (urine, blood), food and beverages. High precision methods, based chiefly on gas chromatography (GC) or high performance liquid chromatography (HPLC) and capillary electrophoresis have been proposed [5]. Some methods based on thin layer chromatography (TLC) require HPTLC system and densitometry [6]. Other methods demand either the hyphenated methodology TLC-MS [7] or fluorescence plate reader [8]. For most schools, such procedures are unrealistic and unfeasible due to the demand of expensive instrumentation, which in addition requires high-cost operation and maintenance.

The aim of the present work is the proposal of simple, fast and low cost procedures for extraction and determination of caffeine content in beverages in commercial products, such as roast and powdered coffee and guarana, as well as beverages. We have used the proposed procedures in laboratory classes for undergraduate and graduate students with satisfactory results. It is expected that the procedures may be feasible also for chemistry teaching at the technical and high school levels. 


\section{Pedagogical Objectives}

The present proposal addresses the general concept of TLC to quantify caffeine in products of every-day consumption. It is a physical and chemical method for separation, detection and quantification of chemicals. In general, the technique is simple, fast and applicable to several research areas of chemistry and biology. It has been used widely in natural products chemistry, aiming at purification of extracts, isolation and identification of representatives or constituents of essential and seed oils, waxes, terpenes, alkaloids, steroids and saponins, among other classes of secondary metabolites. Comparison with commercial standards enables fast screening of substances from plants and commercial products [9].

The basic parameter used to characterize migration of substances by TLC is the $R_{f}$ value [10], which is determined by the formula:

$$
\mathrm{R}_{f}=\frac{\text { distance moved by the substance }}{\text { distance moved by the mobile phase }}
$$

$R_{f}$ values vary from 0 to 1 .

\section{Material and Methods}

\subsection{Material Used for Analysis}

The experiment was planned for analysis of three kinds of material: a medicine tablet, two kinds of powdered products and two beverages. All selected materials are easily available in commerce. The tablet medicine contains caffeine and acetaminophen (paracetamol); it is often used to alleviate headaches and reduce fever and influenza symptoms. The powdered products were guarana and roasted coffee, while the beverages were a canned energy drink (a kola beverage) and a canned yerba mate beverage.

\subsection{Caffeine Extraction}

Finely powdered tablets, guarana and coffee powders ( $0.1 \mathrm{~g}$ of each material) were transferred to Falcon tubes (15 mL capacity). A volume of $0.1 \mathrm{~mL}$ of $0.2 \mathrm{M} \mathrm{NaOH}$ solution of was added to each tube and then $3 \mathrm{~mL}$ of dichloromethane. The tubes were gently shaken by inversion for $5 \mathrm{~min}$, taking care to avoid formation of emulsion. Anhydrous sodium sulfate $(0.5 \mathrm{~g})$ was added, the tubes capped, stirred and then left to stand. With the aid of a Pasteur pipette, the dichloromethane extract of each tube was filtered through Whatman filter paper number 1 (diameter $90 \mathrm{~mm}$ ), previously soaked with dichloromethane, to a glass tube (diameter $1.5 \mathrm{~cm}, 10 \mathrm{~cm}$ high). The residue in each Falcon tube was washed twice with $2 \mathrm{~mL}$ of dichloromethane, the supernatant passed through the filter paper and combined with the previous extract. The solvent in each tube was evaporated to dryness on water bath at $50^{\circ} \mathrm{C}$.

Volumes of $5 \mathrm{~mL}$ of each beverage were transferred to Falcon tubes (15 mL capacity). Sequentially, $0.1 \mathrm{~mL}$ of
$0.2 \mathrm{M} \mathrm{NaOH}$ solution and $3 \mathrm{~mL}$ of dichloromethane were added. The mixture was gently stirred by inverting the tubes ten times, making sure that emulsion does not take place. After standing the tubes until complete separation of two phases, the lower one (dichloromethane) was removed with a Pasteur pipette, filtering it through Whatman filter paper number 1 (diameter $90 \mathrm{~mm}$ ), containing $3 \mathrm{~g}$ of anhydrous sodium sulfate, previously soaked with dichloromethane. The water phase in the Falcon tubes were treated twice with $2 \mathrm{~mL}$ dichloromethane, the tubes were left standing for complete separation of phases and the lower one filtered similarly as described above. The combined extracts were pooled in glass tubes (diameter $1.5 \mathrm{~cm}, 10 \mathrm{~cm}$ high). The solvent in the tubes was evaporated to dryness on water bath at $50{ }^{\circ} \mathrm{C}$.

All analyses of solid and liquid products were carried out in triplicates. The results are expressed as means \pm standard error (SE).

\subsection{Thin-layer Chromatography (TLC)}

The dry extracts obtained were dissolved in exactly $2 \mathrm{~mL}$ of dichloromethane and transferred to Eppendorf tubes previously cooled on ice to prevent evaporation of the solvent. The extracts were analyzed using aluminum TLC plates, coated with silica gel Typ 60 (Merck). With a mechanical pipette, the extracts were deposited $1 \mathrm{~cm}$ from the bottom of the plate and spaced out $1.5 \mathrm{~cm}$ from one another. Each deposit on the plate did not exceed $5 \mu \mathrm{L}$. Total volumes deposited for each extract were: powdered tablet - $4 \mu \mathrm{L}$; coffee powder - $10 \mu \mathrm{L}$; guarana powder - $3.75 \mu \mathrm{L}$; kola beverage - $50 \mu \mathrm{L}$; yerba mate beverage $60 \mu \mathrm{L}$. Three independent plates were prepared with all extracts. The plates were placed inside previously saturated TLC chromatography tanks, containing the mixture ethyl acetate: methanol: ammonium hydroxide (85: 10: 5). The total run of the mobile phase was $18 \mathrm{~cm}$. The visualization of the caffeine spots on the chromatograms were obtained by spray TLC plates with $15 \mathrm{~mL}$ of the reagent ferric chloride: iodine. The reagent was prepared by mixing equal volumes of two solutions: a) $1 \mathrm{~g}$ of iodine dissolved in $25 \mathrm{~mL}$ of acetone; b) $2.5 \mathrm{~g}$ of ferric chloride and $5 \mathrm{~g}$ of tartaric acid, both dissolved in 25 $\mathrm{mL}$ of water. Immediately after the spray, the TLC plate was placed between two glass plates and its image digitalized with a desk scanner (HP Deskjet Ink Advantage 3636), adjusting the analysis to a resolution of 200 dpi.

\subsection{Caffeine Calibration Curve}

Dichloromethane solutions of caffeine at 0.6, 0.8, 1.0, 1.2, 1.4 and $1.6 \mu \mathrm{g} . \mu \mathrm{L}^{-1}$ were used. The solutions were prepared by mixing volumes of a dichloromethane stock solution of caffeine at $10 \mathrm{mg} \cdot \mathrm{mL}^{-1}$ and pure dichloromethane, according to Table 1.

Two successive deposits of $5 \mu \mathrm{L}$ of solutions at each concentration were made on TLC plates. Chromatography analysis, visualization and image digitalization were carried out as described above. Three independent analyses for calibration curve construction were carried out. 
Table 1. Caffeine concentration and volumes of a stock solution of dichloromethane solution at $10 \mathrm{mg} . \mathrm{mL}^{-1}$ and pure dichloromethane for preparation of calibration curve.

\begin{tabular}{cccc}
\hline Caffeine standards $\left(\mathrm{mg} . \mathrm{mL}^{-1}\right)$ & Stock solution of caffeine $(\mu \mathrm{L})$ & Dichloro-methane $(\mu \mathrm{L})$ & Amount of caffeine $(\mu \mathrm{g})$ contained in $10 \mu \mathrm{L}$ \\
\hline 0.6 & 60 & 940 & 6 \\
0.8 & 80 & 920 & 8 \\
1.0 & 100 & 900 & 10 \\
1.2 & 120 & 880 & 12 \\
1.4 & 140 & 860 & 14 \\
1.6 & 160 & 840 & 16 \\
\hline
\end{tabular}

\subsection{Processing of TLC Chromatograms for Determination of Areas of Caffeine Spots}

The areas $\left(\mathrm{mm}^{2}\right)$ corresponding to each of the spots on the chromatograms were determined with the freely available

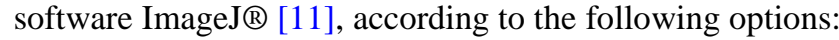
File - Open; Image - Crop (this option focuses the analysis exclusively on the selected TLC spot); Analyze Set scale - Distance in pixels (200); Known distance $25.4 \mathrm{~mm}$; Pixels aspect ratio: 1.0; Unit of length - mm; Image type - 8-bit; Process - Binary - Make Binary; Analyze - Analyze particles; Show - Outlines. With this procedure, the software provides black-and-white images and outlines of each spot and the corresponding areas in square millimeters.

The values of mean areas in $\mathrm{mm}^{2}$ corresponding to the spots on the three TLC chromatograms of the standard solutions were used to obtain the calibration curve and equation of the line.

\subsection{Hazard}

The ideal solvent for caffeine extraction and solubilization is chloroform. However, whenever possible it is recommended to substitute chloroform for another solvent, due to its assumed carcinogenicity. Dichloromethane is a convenient alternate solvent, because of its lower toxicity and efficiency similar to chloroform for caffeine solubilization.

The extraction does not require water boiling temperature (thus reducing risks of accidents in the laboratory) and may be completed in $\mathbf{4 5} \mathrm{min}$, as is the case also of a method reported previously [12].

Safety goggles, gloves and coat should be used to avoid direct contact with reagents. The deposit of the extracts and caffeine standard inside TLC plates were performed with the aid of a fume hood, as well as nebulization of the visualization reagent.

Upon contact with air, solid iodine turns into gaseous iodine by the physical process of sublimation, which may cause eye and skin irritation.

\section{Results and Discussion}

The pellet on the bottom of the tubes after solvent evaporation was relatively plentiful and visible as crystalline needles (Figure 1). This is a positive aspect of introducing caffeine extraction in laboratory classes. The sight of conspicuous crystals provides the students a rewarding feeling of achievement.

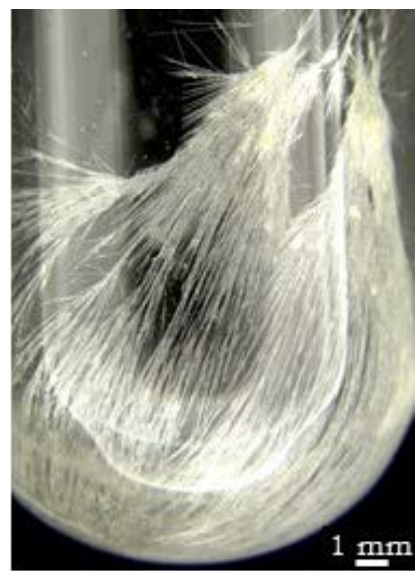

Figure 1. Crystals of caffeine on bottom of glass tube after procedure of extraction from guarana powder

Caffeine $(\mu \mathrm{g})$

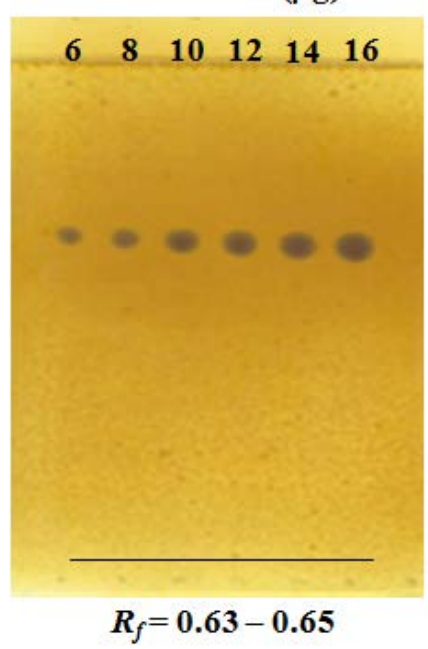

Figure 2. Thin layer chromatogram of dichloromethane solutions with known quantities of caffeine

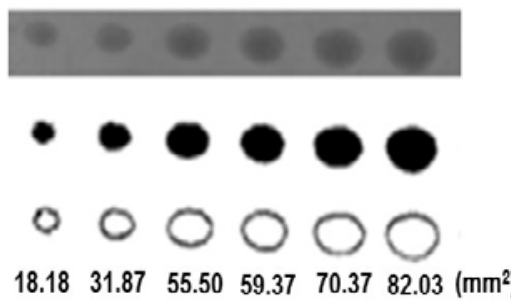

Figure 3. Treatment of the image of chromatogram spots with the software ImageJ. From top to bottom: first layer - digitalized chromatogram spots; second layer - black-and-white converted images of the spots; third layer - outlines of the spots; fourth layer - areas of the spots, as determined by the software 
The TLC analyses took 45 min to complete the $18 \mathrm{~cm}$ run of the solvent. Spots of caffeine appeared immediately after spraying the ferric chloride: iodine visualization reagent. The spots had dark brownish-violet color on a yellow-light brown background, with $\mathrm{R}_{f}$ in the range 0.63-0.65 (Figure 2).

Although no rigorous limit detection has been determined, it is safe to say that $2 \mu \mathrm{g}$ of caffeine may be detected on silica gel layers sprayed with the reagent. The analysis to obtain the calibration curve revealed that within the mass range 6-16 $\mu \mathrm{g}$ the areas of the spots were proportional to the deposited caffeine masses (Figure 3). It was observed that increasing the caffeine mass beyond 16 $\mu \mathrm{g}$ the linear relationship between mass and area is lost, the curve tending to a plateau (data not shown), probably due to a density increase of the spots. As far as the caffeine masses lie in the range of linearity, the areas of the spots alone provide means for the quantification of caffeine, and thus no need of densitometer is required, differently from other reported methods [6,8]. The calibration curve and corresponding regression equation and coefficient of correlation are shown on Figure 4.

The areas of the spots and the contents of caffeine, as determined with the regression equation (Figure 4), are given on Table 2. On the same table are given the expected contents based on information provided by the description leaflet of the medicine tablet, the bottle labels (energy drink, yerba mate beverage) or literature about the product (coffee and guarana powders). Standard errors regarding the determined caffeine contents varied in the range $1.9 \%$ (yerba mate beverage) to $6.5 \%$ (kola soft drink). Such fluctuation is too high if precision in the values to be determined is essential. However, if high precision is not a crucial requisite, the fluctuation found seems to be not prohibitive.
The contents of caffeine determined for coffee and guarana powder, as well for the yerba mate beverage, lie within the variation range admitted for the products (Table 2). Regarding the content of caffeine found for the kola drink and the tablet medicine, the means of the values found were $15 \%$ and $8 \%$ lower than the amount of caffeine declared by the producer companies. Depending on the accuracy expected for procedures to be used in laboratory classes of chemistry, the results obtained may be considered satisfactory. The disadvantage regarding the lack of a high degree of precision of the proposed method is compensated by the feasibility of its implementation in laboratory classes. Since the method requires neither costly chemicals nor expensive equipment, it may be adequate not only for education at the university level, but also for students at technical schools. Hopefully, the procedures might be adapted even for teaching at high school level, as far as the establishments have facilities enabling simple experiments in chemistry or biochemistry.

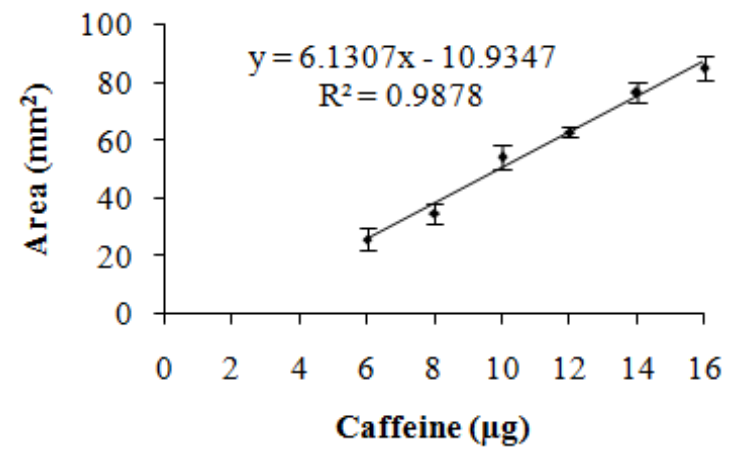

Figure 4. Calibration curve relating quantities of caffeine analyzed by thin layer chromatography and areas of the corresponding spots, regression equation and correlation coefficient

Table 2. Caffeine content (mg) and corresponding alleged amount of medicine and commercial products. Results are expressed as triplicate means $\pm \mathrm{SE}$

\begin{tabular}{lccc}
\hline Product & $\begin{array}{c}\text { Volume of extract } \\
\text { deposited }(\boldsymbol{\mu L})\end{array}$ & $\begin{array}{c}\text { Area of the TLC spot } \\
\left(\mathbf{m m}^{2}\right)\end{array}$ & $\begin{array}{c}\text { Caffeine content (mg) } \\
\text { expected }(\mathbf{m g})\end{array}$ \\
\hline Medicine tablet (1 tablet) & 4 & $67.4 \pm 4.4$ & $42.3 \pm 1.4$ \\
Coffee powder (\%) & 10 & $62.0 \pm 0.1$ & $2.4 \pm 0.1$ \\
Guarana powder (\%) & 3.75 & $47.9 \pm 0.9$ & $5.1 \pm 0.1$ \\
Kola soft drink (350 mL) & 50 & $59.7 \pm 2.1$ & $32.2 \pm 1.2$ \\
Yerba mate drink (330 mL) & 60 & $46.2 \pm 1.1$ & $2.5^{13}$ \\
\hline
\end{tabular}

${ }^{a}$ Declared on the drug leaflet; ${ }^{b}$ mass/mass.

\section{Conclusion}

The proposed procedure enables a low cost and rapid extraction and quantification of caffeine in food and beverages. Although not applicable in case high precision is crucial, the procedures provide approximate values and are feasible for chemical education at universities and technical schools.

\section{Acknowledgements}

AS and MLFS are fellow researchers of CNPq (Conselho Nacional do Desenvolvimento Científico e Tecnológico, Brazil).

\section{References}

[1] Frary, C. D.; Johnson, R. K.; Wang, M. Q. Food sources and intakes of caffeine in the diets of persons in the United States. J Am Diet Assoc. 2005, 105(1), 110-113.

[2] Heckman, M. A.; Weil, J.; Mejia, D.; Gonzalez, E. Caffeine (1,3,7-trimethylxanthine) in foods: a comprehensive review on consumption, functionality, safety, and regulatory matters. J. Food Sci. 2010, 75(3), 77-87.

[3] Available at:

https://www.fda.gov/downloads/aboutfda/centersoffices/ officeoffoods/cfsan/cfsanfoiaelectronicreadingroom/ucm333191.p df. Accessed May 09, 2017.

[4] Li, J.; Zhao, H.; Song, J. M.; Zhang, J.; Tang, Y. L.; Xin, C. M. A meta-analysis of risk of pregnancy loss and caffeine and coffee consumption during pregnancy. Int J of Gynecol Obstet. 2015, 130(2) 116-122. 
[5] De Maria, C. A.; Moreira, R. F. Analytical methods for caffeine. Química Nova. 2007. 30(1), 99-105.

[6] Priyamvada, S.; Murthy, P.; Shivhare, P. Validated highperformance thin layer chromatography for caffeine quantification in beverages and edibles. Int. J. Clin. Toxic. 2014, 2: 31-36.

[7] Prošek, M.; Golc-Wondra, A.; Vovk, I.; Andrenšek, S. Quantification of caffeine by off-line TLC-MS. $J$ Planar Chromatogr-Modern TLC. 2000, 13, 452-456.

[8] Tavallali, H.; Zareiyan, S. F.; Naghian, M. An efficient and simultaneous analysis of caffeine and paracetamol in pharmaceutical formulations using TLC with a fluorescence plate reader. J AOAC Int. 2010, 94(4), 1094-1099.

[9] Waksmundzka-Hajnos, M., Sherma, J., \& Kowalska, T. (Eds.). Thin layer chromatography in phytochemistry. CRC Press. 2008.

[10] Sherma, J., \& Fried, B. (Eds.). Handbook of thin-layer chromatography (Vol. 89). CRC press. 2003.

[11] Available at:

https://imagej.nih.gov/ij/download.html (accessed June 2017).
[12] Onami, T.; Kanazawa, H. A. Simple Method for Isolation of Caffeine from Black Tea Leaves: Use of a DichloromethaneAlkaline Water Mixture as an Extractant. J. Chem. Educ. 1996, 73(6), 556-557.

[13] Available at: http://www.abic.com.br/publique/cgi/cgilua.exe/sys/ start.htm?sid=279 (accessed June 2017).

[14] Available at: http://www.rain-tree.com/guarana.htm\#.WQz5PojyvIX (accessed June 2017).

[15] Available at: http://www.cocacolabrasil.com.br/nosrespondemos/ingredientes/uma-lata-de-coca-cola-tem-metade-dacafeina-de-uma-xicara-de-cafe (accessed June 2017).

[16] Available at https://www.megustaveg.com.br/cha-mate-organiconatural-tearapy (accessed June 2017)

[17] Available at http://www.medclick.com.br/saude/2014/06/quantidade-decafeina-em-alimentos-e-bebidas/ (accessed June 2017). 